\title{
Frederick Law Olmsted: a arquitetura de paisagens e os parques nacionais norte-americanos
}

\author{
Juliana da Costa Gomes de Souza ${ }^{1 *}$ \\ ${ }^{1}$ Universidade de Brasília, Brasília/ DF - Brasil \\ José Luiz de Andrade Franco ${ }^{2 * *}$ \\ ${ }^{2}$ Universidade de Brasília, Brasília/ DF - Brasil
}

\section{RESUMO}

O presente estudo se insere no campo da história ambiental, trata da arquitetura de paisagens e do seu precursor, o arquiteto paisagista Frederick Law Olmsted. A análise dos escritos de Olmsted, de figuras importantes para sua formação pessoal e profissional, e a compreensão do contexto no qual ele se destacou têm forte relação com a proteção à natureza. $\mathrm{O}$ objetivo deste artigo consiste em compreender o contexto em que se desenvolveu o trabalho de Olmsted e a sua relaçáo com os primeiros parques nacionais norte-americanos. As conclusóes da pesquisa destacam: i) a percepção de Olmsted de que se devia buscar uma relação saudável entre humanos e a natureza; ii) e o seu legado para a sociedade norte-americana do século XIX, especialmente no que diz respeito à questáo da valorização da natureza selvagem.

Palavras-chave: história ambiental; wilderness; proteção da natureza; Central Park; Yosemite.

\section{Frederick Law Olmsted: Landscape Architecture and North American National Parks}

\section{ABSTRACT}

The present study contributes to the field of environmental history and deals with landscape architect Frederick Law Olmsted. This article analyzes Olmsted's writings, important figures in his personal and professional formation, and the context in which he rose to fame, all of

DOI: http://dx.doi.org/10.1590/2237-101X02104510.

Artigo recebido em $1^{\circ}$ de julho de 2019 e aceito para publicação em 16 de março de 2020.

* Pesquisadora da Universidade de Brasília / Centro de Desenvolvimento Sustentável, Brasília / DF - Brasil.

E-mail: jcgdesouza@gmail.com. ORCID: https://orcid.org/0000-0001-9713-1629.

** Professor da Universidade de Brasília / Centro de Desenvolvimento Sustentável / Departamento de História, Brasília/ DF - Brasil. E-mail: jldafranco@terra.com.br. ORCID: https:/orcid.org/0000-0001-67726234. 
which shaped his conception of protecting nature. This article's purpose is to understand the context in which Olmsted's work developed, as well as his work's relationship with North America's first national parks. Its conclusions highlight: i) Olmsted's perception that a healthy relationship between humans and nature should be sought, and ii) his legacy in nineteenth-century American society, especially regarding to the question of valuing wilderness.

Keywords: environmental history; wilderness; protection of nature; Central Park; Yosemite.

\section{Frederick Law Olmsted: la arquitectura de paisajes y los parques nacionales norteamericanos}

\section{RESUMEN}

El presente estudio se insiere en el campo de la historia ambiental, trata de la arquitectura de paisajes y de su precursor, el arquitecto paisajista Frederick Law Olmsted. El análisis de los escritos de Olmsted, de figuras importantes para su formación personal y profesional, y la comprensión del contexto en el cual él se destacó tiene fuerte relación con la protección a la naturaleza. El objetivo de este artículo consiste en vislumbrar el contexto en el que se desarrolló el trabajo de Olmsted y su relación con los primeros parques norteamericanos. Las conclusiones de la investigación destacan i) la percepción de Olmsted de que se debía buscar una relación saludable entre humanos y la naturaleza; ii) y su legado para la sociedad norteamericana del siglo XIX, especialmente en lo que respecta a la valorización de la naturaleza salvaje.

Palabras clave: historia ambiental; wilderness; protección de la naturaleza; Central Park; Yosemite.

\section{Introdução}

O objetivo deste artigo consiste em compreender o contexto em que se desenvolveu a arquitetura de paisagens de Frederick Law Olmsted (1822-1903) e a sua relaçáo com os primeiros parques nacionais norte-americanos. Importante destacar que, por trabalhar as relaçôes entre humanos e natureza, esse trabalho se insere no campo da história ambiental.

Olmsted foi um profissional com vasta experiência em diversos setores. Trabalhou com agricultura, engenharia, jornalismo e participou de lutas sociais e pela conservação da natureza (Figura 1). As experiências de vida de Olmsted estiveram fortemente ligadas ao de- 
senvolvimento da arquitetura de paisagens e a um contexto histórico no qual os espaços de natureza selvagem (wilderness) se tornavam cada vez mais relevantes.

Nascido em 26 de abril de 1822, em Hartford, estado de Connecticut, Estados Unidos da América (EUA), Olmsted ficou conhecido como o pai da arquitetura de paisagens norte-americana. Ele foi também jornalista, administrador público e ativista do movimento conservacionista. Tornou-se famoso por criar com Calvert Vaux (1824-1895) ${ }^{3}$, arquiteto e paisagista britânico, alguns dos mais famosos parques urbanos dos EUA, como o Central Park, em Nova York (1857), e o Golden Gate Park, em San Francisco (1870). Olmsted ficou conhecido também por criar o primeiro sistema de vias interligadas a parques urbanos em Buffalo, Nova York (1868), e por restaurar o Niagara Reservation State Park, ao longo das Niagara Falls (1865). Ele foi o responsável por propor o relatório do Yosemite Valley, na Califórnia, em 1865, que consumou a proteção do vale (CRONON, 1996; NASH, 1990).

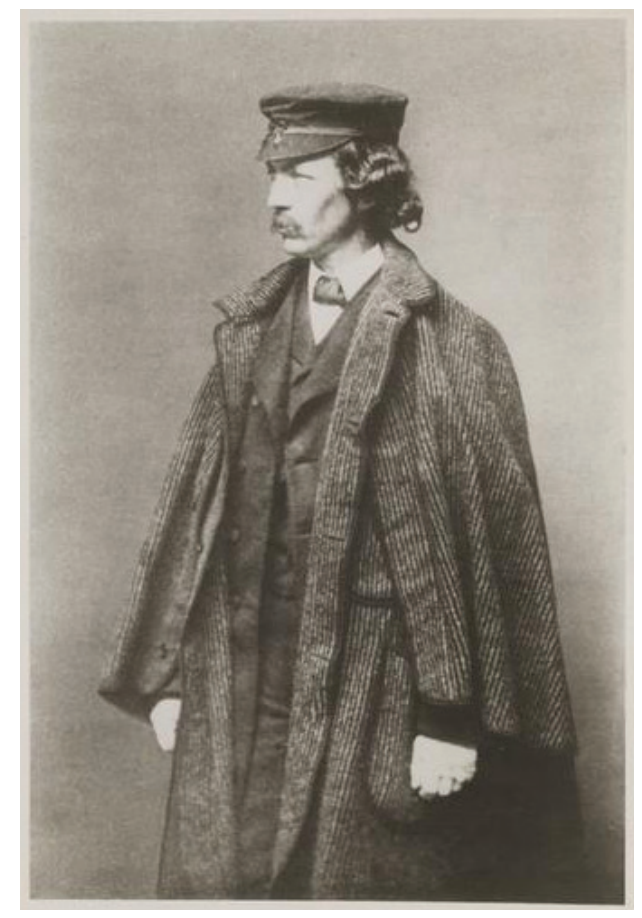

Figura 1: Frederick Law Olmsted, 1860. Disponível em: https://collections.mcny.org/Collection/ Frederick\%20Law\%20Olmsted-24UFQELKHX0.html

\footnotetext{
${ }^{3}$ Calvert Vaux nasceu em 1824, em Londres, Inglaterra, onde permaneceu até 1850 trabalhando como arquiteto e paisagista aprendiz no escritório do arquiteto britânico Lewis Nockalls Cottingham (1787-1847). Em 1851, o trabalho de Vaux chamou a atenção de Andrew Jackson Downing, que o convidou para trabalhar em seu escritório em Newburgh, Nova York. Vaux aceitou e, nesse mesmo ano, conheceu Olmsted, que viajou a Newburgh para visitar Downing. Com a morte precoce de Downing, Vaux assumiu o controle do escritório do qual já era sócio e, em 1857, convidou Olmsted para elaborar, conjuntamente, uma proposta de projeto para o concurso do Central Park. O projeto de Vaux e Olmsted foi vencedor do concurso, e essa parceria durou até 1872. Vaux faleceu no Brooklyn, Nova York, em 1895 (FEIN, 1972; KOWSKY, 2003).
} 
Nos EUA do século XIX, um dos grandes debates girava em torno da questấo da identidade nacional. A expansão das cidades, a industrialização e, por conseguinte, a degradação dos ambientes e a queda na qualidade de vida urbana e do solo cultivado levaram à discussão da necessidade de conservação da natureza. As filosofias romântica e transcendental elevaram a importância da natureza selvagem e ajudaram a estabelecer um vínculo entre wilderness e a identidade nacional norte-americana. A preocupação com a perda da natureza selvagem necessariamente precedeu os primeiros pedidos de sua proteção. Essa iniciativa teve origem na mesma classe social que posteriormente liderou o caminho para a valorização da wilderness: artistas, escritores e filósofos (NASH, 2001 [1967]; STOLL, 2015).

George Catlin (1796-1872), pintor de índios norte-americanos, foi o primeiro a efetivamente clamar pela proteção da natureza ao propor a criação do parque de Yellowstone em 1832. Frederic Edwin Church (1826-1900), primo distante de Olmsted e pintor paisagista norte-americano, retratou as Niagara Falls em 1857, tornando-se um grande defensor dessa beleza natural. O escritor Ralph Waldo Emerson (1803-1882) liderou o movimento transcendentalista, cujo cerne era a crença de que havia uma correspondência entre uma esfera superior de verdade espiritual e uma esfera inferior de objetos materiais. Por refletir as verdades espirituais universais, os objetos naturais assumiam importância. Emerson declarou em seu manifesto Nature, de 1836, que a natureza era o símbolo do espírito. Influenciado por Emerson e Catlin, o filósofo Henry David Thoreau (1817-1862) desejava impedir a extinção de índios e animais selvagens, defendeu a wilderness como reservatório de nutrição intelectual aos humanos e foi além: argumentou que proteger a wilderness era importante para a preservação da própria civilização (FONER, 2017 [2005]; MARTIN, 2011; NICHOLSON, 2004; STOLL, 2015).

Os pensadores citados e demais outros iniciaram os debates sobre a necessidade de proteção da natureza, como uma contracorrente ao desenfreado processo civilizatório da marcha para Oeste. Até culminar em um debate mais profundo sobre o valor intrínseco da natureza, foram necessários diversos outros que expandiriam o círculo de ética e de leis relacionados a abolição da escravidão, direitos das mulheres, direitos dos animais e direitos da nature$\mathrm{za}^{4}$. Foi durante esse processo que surgiram os primeiros parques nacionais e instituiçóes a eles relacionadas como, por exemplo, o U.S. National Park Service (NPS), criado em 1916 (CARR, 1999; NASH, 1989; SELLARS, 1997).

Com a expansão do círculo de ética e a conscientização da população, a wilderness passou a ser um dos bens mais expressivos e valorizados pelos norte-americanos, tornando-se um

\footnotetext{
${ }^{4}$ Nash (1989) considera que a evolução das relações entre humanos e natureza passa por uma expansão da ética nessas relaçôes e isso se reflete na ampliação de direitos. No "Prólogo" há dois gráficos (p. 5 e p. 7) que explicam como ética e direitos se expandem. A expansão ética foi dividida em quatro momentos: passado pré-ética, ética passada, presente e futuro. O estágio inicial é o próprio ser e o estágio final é a relação que os seres estabelecem com o universo. A expansão dos direitos parte dos direitos naturais humanos até alcançar os direitos da natureza, expressado simbolicamente pelo Endangered Species Act, de 1973.
} 
símbolo da identidade nacional nos EUA (MUMFORD, 1998 [1961]; NASH, 2001 [1967]). A criação de parques nacionais, mesmo que inicialmente dentro de um viés mais utilitarista, consolidou o início dos debates sobre proteção da natureza e permitiu a continuidade de discussóes sobre o assunto. Olmsted, utilizando a sua experiência em arquitetura de paisagens e em administração e gerenciamento, elaborou um relatório para a criação daquele que deveria ter sido o primeiro parque nacional norte-americano, no Yosemite Valley. Apesar de não ter sido aceito pela legislatura da Califórnia, o ato de criação do parque e o seu relatório serviram como estímulo para a organização de outros parques nacionais, como foi o caso do Parque Nacional de Yellowstone, em 1872, que de fato foi o primeiro parque nacional a ser criado nos EUA e no mundo.

Para compreender a vida e o pensamento de Olmsted, foram analisados vários de seus manuscritos autobiográficos ou textos publicados. Duas coletâneas foram utilizadas como fonte de pesquisas desses manuscritos, a de Beveridge (2016) e de Hubbard e Olmsted Jr. (2018 [1922])5. Alguns dos manuscritos utilizados foram nomeados por Olmsted, outros, como cartas e rascunhos, não possuem título. Os trechos sobre o plano do Central Park, Description of a Plan for the Improvement of the Central Park (1865), foram retirados do documento completo presente na coletânea de Beveridge (2016). O documento sobre a infância de Olmsted, Passages in the Life of an Unpractical Man (s.d.); a carta para Andrew Jackson Downing (1850); e a carta a uma amiga (meados de 1890) foram retirados da coletânea de Hubbard e Olmsted Jr. (2018 [1922]). O livro de Olmsted, The Yosemite Valley and the Mariposa Grove of Big Trees: a Preliminary Report, 1865 (2014 [1865]), trata do relatório para a criação do Parque Nacional do Yosemite. Foram utilizadas passagens do livro Walks and Talks of an American Farmer in England (1852), também de Olmsted, e dos livros de Downing (1841), Gilpin (1791) e Price $(1810)^{6}$. Os trechos dessas três últimas fontes deixam clara a influência do romantismo e da arquitetura orgânica no trabalho de Olmsted.

As obras do historiador ambiental Roderick Nash também mencionam as contribuições de Frederick Law Olmsted, porém de forma pontual. Sua maior contribuição a esse estudo está relacionada com a contextualização de Olmsted na história da proteção da natureza norte-americana. Trabalham mais diretamente a vida e as obras de Olmsted, os autores Cronon (1996), Fein (1972) e Martin (2011). Sobre a arquitetura de paisagens, Carr (1999), Emidio (2017), Laurie (1976), Panzini (2013) e Sellars (1997) fornecem as informaçóes para melhor compreensão da profissão.

\footnotetext{
${ }^{5}$ Intitulada Frederick Law Olmsted, Landscape Architect, 1822-1903 e publicada pela primeira vez em 1922, centenário de nascimento de Frederick Law Olmsted, essa foi a primeira coletânea de textos escritos por Olmsted. Foi organizada por seu filho, Olmsted Jr. (1870-1957), e pela bibliotecária da Harvard School of Landscape Architecture, Theodora Kimball Hubbard (1887-1935).

${ }^{6}$ Os livros de Downing (1841), Gilpin (1791), Olmsted (1852) e Price (1810) foram obtidos por meio do site Internet Archive (archive.org). A Internet Archive é uma organização sem fins lucrativos que disponibiliza gratuitamente documentos digitalizados anteriores a 1923 e sem copyright.
} 
Cronon (1996) além de descrever alguns dos projetos de Olmsted e um pouco da vida do arquiteto de paisagens, fez uma observação em seu livro sobre a necessidade de resgatar a importância de Olmsted para a arquitetura de paisagens norte-americana. A partir da década de 2000, principalmente, diversos livros de Olmsted e coletâneas de seus escritos vêm sendo republicados, a exemplo de Olmsted (2014 [1865]) e Hubbard e Olmsted Jr. (2018 [1922]). Obras sobre a vida de Olmsted também vêm ganhando destaque, como Martin (2011). No entanto, a literatura não relaciona de forma direta - ou faz brevemente essa relação, como Carr (1999) - a influência de Olmsted e de sua arquitetura de paisagens na criação dos primeiros parques nacionais norte-americanos. Este artigo busca suprir, de maneira não exaustiva, essa lacuna de conhecimento, proporcionando espaço para demais pesquisas e discussóes sobre o tema.

A pesquisa foi organizada em duas partes: "A emergência da arquitetura de paisagens de Frederick Law Olmsted" e "A arquitetura de paisagens no Central Park e nos parques nacionais". Na primeira parte desenvolvemos uma narrativa baseada na vida de Olmsted, com foco nos fatores e nas pessoas que o influenciaram a trabalhar com arquitetura de paisagens. A segunda parte é uma descrição mais técnica de como ele inicialmente trabalhou suas habilidades, em parceria com o arquiteto Calvert Vaux, e uma análise de como a arquitetura de paisagens de Olmsted se relaciona com a proteção da natureza em parques nacionais. $\mathrm{Na}$ conclusão, chamamos a atenção para a percepção de Olmsted de que se devia buscar uma relação saudável entre humanos e a natureza e para o seu legado para a sociedade norte-americana do século XIX, e para a atualidade, no que diz respeito à questão da proteção da natureza selvagem.

\section{A emergência da arquitetura de paisagens de Frederick Law Olmsted}

Nos EUA do século XIX, emergia um estilo pitoresco de projetar paisagens. Esse estilo foi importado da Inglaterra, onde estava presente desde o século XVIII. Foi o arquiteto e paisagista britânico Lancelot Brown (1716-1783) quem iniciou a melhoria dos parques ingleses seguindo o que ele entendia como "visão pitoresca". Essa visão pitoresca foi muito influenciada pela pintura e poesia românticas, que idolatravam a natureza selvagem e sua contemplação por meio de aspectos como o belo, o pitoresco e o sublime. A pintura foi de suma importância para a valorização da wilderness, pois servia como um instrumento fundamental para a educaçấo do olhar sobre sua beleza (CARR, 1999; EMIDIO, 2017; PANZINI, 2013; SEGAWA, 1996).

A discussão sobre os três últimos conceitos foi feita por diversos artistas românticos, com destaque para o pintor e reverendo britânico William Gilpin (1724-1804) e o aristocrata britânico Sir Uvedale Price (1747-1829). Em termos gerais, esses autores definiam o pitoresco 
como aquilo que é próprio de ser retratado em uma pintura, o belo como o que é agradável aos olhos e o sublime como aquilo que transcende a compreensão humana e valoriza a natureza não domesticada (GILPIN, 1791; PRICE, 1810). Dessa maneira, alterações da paisagem com base na visão pitoresca resultavam em valorização de uma natureza mais próxima da prístina e na presença de poucos elementos construídos (CARR, 1999; EMIDIO, 2017; PANZINI, 2013).

O sucessor de Brown, o paisagista britânico Humphry Repton (1752-1818), descreveu como "jardinagem paisagista" o desenho paisagístico pitoresco advindo da Inglaterra. O paisagista escocês John Claudius Loudon (1783-1843) seguiu o mesmo modo de projetar de seus antecessores. A carreira do horticultor norte-americano Andrew Jackson Downing $(1815-1852)^{7}$ foi moldada com base no trabalho de Claudius Loudon. Downing foi o responsável por aplicar nos EUA o estilo pitoresco no trabalho de jardinagem paisagista, passando a influenciar demais profissionais norte-americanos (CARR, 1999; EMIDIO, 2017; PANZINI, 2013).

Downing publicou, em 1841, A Treatise on the Theory and Practice of Landscape Gardening, Adapted to North America: with a View to the Improvement of Country Residences. Nesse livro, ele tratava da arquitetura de paisagens, ou jardinagem paisagista, como uma maneira de incentivar a civilidade por meio do cuidado com a natureza na escala doméstica. A natureza além de bela era moralmente benéfica (DOWNING, 1841; HUBBARD; OLMSTED JR., 2018 [1922]; SEGAWA, 1996). Além disso, o horticultor apontava dois tipos diferentes de arte e sua aplicação na paisagem: "Todos os autores recentes concordam nesses dois modos distintos e amplamente diferentes da arte; $1^{\circ}$, estilo antigo, formal ou geométrico; $2^{\circ}$, estilo moderno, natural ou irregular" (DOWNING, 1841, p. 12) ${ }^{8}$. Esse último estilo era o também chamado pitoresco.

O principal instrumento de trabalho dos profissionais da jardinagem paisagista é a paisagem. No entanto, o conceito de paisagem é variado e variável, pois se encontra atrelado a dinâmicas naturais e sociais (EMIDIO, 2017). Dessa maneira, o conceito de arquitetura de paisagens também alterou ao longo do tempo. A descrição da profissão por Hubbard e Kimbal é uma das mais próximas da arquitetura de paisagens praticada nos EUA do século XIX, pois

\footnotetext{
${ }^{7}$ Andrew Jackson Downing nasceu em Newburgh, Nova York, em 1815. Ficou conhecido como o precursor da jardinagem paisagista nos EUA, defensor da melhoria da vida no campo por meio de uma arquitetura rural e difusor do uso da varanda nas casas norte-americanas. Ele foi o elo entre a jardinagem paisagista britânica e norte-americana. Seu estilo de projetar era orgânico (pitoresco) e influenciou a futura geração de arquitetos de paisagens norte-americanos. Horticultor e escritor, era editor na revista The Horticulturist and Journal of Rural Art and Rural Taste, mais conhecida como The Horticulturist, e possuía um escritório de jardinagem paisagista em Newburgh. Faleceu aos 36 anos, em 1852, em uma explosáo de um barco a vapor no rio Hudson (CARR, 1999; FEIN, 1972; STOLL, 2015).

${ }^{8}$ Todas as citaçóes de fontes e obras de autores em língua estrangeira foram traduzidas pelos autores deste artigo. No original: "All late authors agree in these two distinct and widely differing modes of the art; $1^{\text {st }}$, the Ancient, Formal or Geometric Style; $2^{\mathrm{d}}$ (sic), the Modern, Natural or Irregular Style".
} 
associa a criação da beleza e do conforto à saúde das populaçôes urbanas (LAURIE, 1976). Foi nesse contexto que emergiu a arquitetura de paisagens de Olmsted. A arquitetura de paisagens não foi, porém, sua escolha consciente, mas uma consequência de suas experiências pessoais e profissionais, também influenciadas pelo contexto histórico norte-americano do século XIX. Olmsted tinha o hábito de escrever sobre suas ideias e experiências de viagens, e de trocar correspondências com amigos e parentes. Por meio de seus vários escritos, foi possível compreender as origens de sua apreciaçáo da natureza e como ela evoluiu para a prática da arquitetura de paisagens (HUBBARD; OLMSTED JR., 2018 [1922]).

Além dos passeios e viagens que realizava com sua família desde pequeno com o intuito de apreciar a natureza, a educação de Olmsted também o direcionou para a arquitetura de paisagens. A sua educação primária, de 1826 a 1837, ocorreu em várias escolas no meio rural de Connecticut, onde ele aproveitava para fazer pequenas incursóes nas florestas dos arredores e já praticava intuitivamente a apreciação da paisagem. Entre 1837 e 1844, ele exerceu diversas atividades práticas, desde ajudante de engenheiro civil, balconista numa firma de importação de grãos até aprendiz de atividades agrícolas (FEIN, 1972; HUBBARD; OLMSTED JR., 2018 [1922]).

Os estudos práticos em engenharia, iniciados em novembro de 1837, despertaram o interesse de Olmsted por leituras que discutiam questôes como o pitoresco, o belo e o sublime na paisagem. Duas obras sobre esses assuntos foram destacadas como primordiais nos seus fragmentos autobiográficos: Remarks on forest scenery, and other woodland views (related chiefly to picturesque beauty), illustrated by the scenes of New Forest in Hampshire (1791), de Gilpin, e Essays on the Picturesque, as Compared with the Sublime and the Beautiful: and, on the Use of Studying Pictures, for the Purpose of Improving Real Landscape, Volume 1 (1810), de Price (HUBBARD; OLMSTED JR., 2018 [1922]; PRICE, 1810).

A leitura de Gilpin (1791) e Price (1810) indicava que Olmsted acompanhava o movimento romântico, no âmbito do qual a valorizaçấo da natureza selvagem apresentava-se como um aspecto central. Além desses autores, ele também lia Emerson, entre outros pensadores influentes na época (HUBBARD; OLMSTED JR., 2018 [1922]; NASH, 2001 [1967]; PRICE, 1810). Sobre Gilpin (1791) e Price (1810), Olmsted escreveu, por volta de 1890, em uma carta a uma amiga não identificada:

Eles eram Price em The Picturesque e Gilpin em Forest Scenery, - livros do século passado, mas que eu aprecio muito mais do que qualquer outro publicado desde então, como estimulando o exercício do julgamento em questóes de minha arte, que eu os colocava nas mãos dos meus alunos assim que entravam em nosso escritório, dizendo: "Você deve ler isso seriamente, como um estudante de direito leria Blackstone" (OLMSTED, 1890, 1. 945-950).?

\footnotetext{
${ }_{9}^{9}$ No original: "They were Price on the Picturesque and Gilpin on Forest Scenery, - books of the last century, but wich I esteem so much more than any published since, as stimulating the excercise of judgment in
} 
Nessa mesma carta, Olmsted comentou sobre Emerson: "Naquela época, fui levado a Emerson, Lowell e Ruskin e a outros profetas de verdade que são amigos familiares desde então [...]. E isso me deu o respeito necessário pelos meus próprios gostos constitucionais e uma inclinação ao refinamento poético em seu cultivo que depois determinou minha profissão" (OLMSTED, 1890, 1. 941-945) ${ }^{10}$. O escritor romântico John Ruskin (1819-1900), citado por Olmsted, assim como o naturalista Alexander von Humboldt (1769-1859), foram também grandes influentes da arte e estudo da paisagem (STOLL, 2015). Dessa maneira, fica clara a influência dos pensadores românticos e das influências do estilo pitoresco na vida de Olmsted desde a sua juventude, marcando sua futura formação como arquiteto de paisagens.

Em 1836, Olmsted sofreu um grave envenenamento por sumagre, que o cegou parcialmente, prejudicando sua visão por diversos anos. Apesar disso, ele conseguiu finalizar sua educação primária ainda em 1836. Por recomendação médica, foi aconselhado a não exercer atividades que forçassem muito a visão, o que o afastou dos estudos universitários. Nos anos de 1842, 1846 e 1847, Olmsted frequentou palestras sobre agricultura na Yale University, New Haven, Connecticut. Em 1846, ele chegou a estudar um semestre na universidade com o geólogo e químico Benjamin Silliman (1779-1864), fator crucial para que Olmsted decidisse trabalhar com agricultura. Nesse mesmo ano, Olmsted trabalhou como aprendiz em uma fazenda de Onondaga County, Nova York. No ano seguinte, ele comprou uma fazenda em Staten Island, Nova York, onde passou a praticar seus conhecimentos em agricultura e onde residiu por dez anos, período de importantes acontecimentos, responsáveis pela sua sutil transição de agricultor para arquiteto de paisagens (FEIN, 1972; STOLL, 2015).

Em 1849, Olmsted realizou uma série de viagens curtas com a finalidade de adquirir mudas para iniciar seu pequeno viveiro. As despesas eram pagas com os artigos que ele escrevia sobre temas agrícolas para jornais e revistas. Uma dessas revistas era a The Horticulturist, que tinha o paisagista e horticultor Andrew Jackson Downing como editor. Em 1850, Olmsted realizou uma viagem à Inglaterra e à Europa Ocidental, e relatou, em uma carta a Downing, algumas de suas experiências dessa viagem: "Vi as melhores partes da Inglaterra, passando dois meses viajando a pé, vendo o país com grande vantagem, de modo que sinto como se não tivesse apenas visto o caráter rural, mas vivido nele, e fiz dele uma parte de mim" (OLMSTED, 1850, 1. 1238-1243) ${ }^{11}$. Nessa mesma carta, Olmsted

matters of my art, that I put them into the hands of my pupils as soon as they come into our office, saying, "You are to read these seriously, as a student of law would read Blackstone"'.

${ }^{10}$ No original: "[...] I was led up at that time to Emerson, Lowell and Ruskin, and other real prophets who have been familiar friends ever since. [...]. And these gave me the needed respect for my own constitucional tastes and an inclination to poetical refinement in the cultivation of them that afterwards determined my profession".

${ }^{11}$ No original: "I saw the best parts of England, spending two months travelling through it on foot, seeing the country of course to great advantage, so that I feel as if I had not merely seen the rural character, but lived in it, and made it a part of me". 
pediu sugestóes a Downing sobre diferentes maneiras de cultivar determinadas espécies de plantas, como peras.

A relação entre Olmsted e Downing era profissional e refletia a admiração e o respeito que Olmsted tinha por Downing. Em 1851, ele visitou Downing em seu escritório em Newburgh, Nova York, onde conheceu seu futuro sócio, Calvert Vaux. Dessa maneira, além de influenciar Olmsted em seu estilo de trabalhar a arquitetura de paisagens e a agricultura, chegando até mesmo a vender mudas de seu viveiro para Olmsted, Downing foi o elo entre Olmsted e Vaux (FEIN, 1972; MARTIN, 2011; STOLL, 2015). No ano seguinte, Olmsted publicou seu primeiro livro: Walks and Talks of an American Farmer in England (HUBBARD; OLMSTED JR., 2018 [1922]). No livro, Olmsted relatou suas observaçóes sobre o paisagismo europeu, tendo se impressionado principalmente com o britânico, berço da jardinagem paisagística e do estilo pitoresco. Ele descreveu o People's Garden, em Birkenhead, o mais importante subúrbio de Liverpool, como dotado de um paisagismo perfeito:

Cinco minutos de admiração, e alguns mais gastos estudando a forma com que a arte foi empregada para obter da natureza tanta beleza, e eu já estava pronto para admitir que na América democrática não havia nada a ser pensado de comparável a este People’s Garden. De fato, a jardinagem aqui alcançou a perfeição que eu nunca antes havia imaginado. [...] eu vou apenas dizer-lhes que passamos por caminhos sinuosos por acres e acres, com uma constante variaçáo de superfície, onde por todos os lados cresciam todas as variedades de arbustos e flores, com mais que graça natural, todos dispostos nas bordas dos gramados mais verdes, próximos à relva e mantidos na maior perfeição (OLMSTED, 1852, p. 89, grifo nosso). ${ }^{12}$

O livro de Olmsted teve seu impacto social e trazia algumas observaçôes além daquelas referentes ao estilo pitoresco e à natureza ${ }^{13}$. Sobre a visão dos europeus relacionada à escravidão, Olmsted escreveu: "Todas as pessoas mais moderadas e religiosas têm um grande horror de nossa escravidáo e das ocasionais atuaçóes da lei de Lynch em nossa fronteira oci-

\footnotetext{
${ }^{12}$ No original: "Five minutes of admiration, and a few more spent in studying the manner in which art had been employed to obtain from nature so much beauty, and I was ready to admit that in democratic America there was nothing to be thought of as comparable with this People's Garden. Indeed, gardening had here reached a perfection that I had never before dreamed of. [...] I will only tell you, that we passed by winding paths over acres and acres, with a constant varying surface, where on all sides were growing every variety of shrubs and flowers, with more than natural grace, all set in borders of greenest, closest turf, and all kept with most consummate neatness".

${ }^{13}$ A inclusão de assuntos sociais no livro de Olmsted seguiu uma tendência da época. A revolução do mercado pela qual os EUA passaram nas primeiras décadas do século XIX levou desenvolvimento tecnológico e proporcionou a expansão urbana. Questóes como imigração, desigualdades sociais e escravidão tornaram-se necessárias serem discutidas. Em 1852, a escritora Harriet Beecher Stowe (1811-1896) publicou o livro Uncle Tom's Cabin, um romance sobre a escravidáo norte-americana, que ajudou a estabelecer as bases para a luta abolicionista e para a Guerra Civil (1861-1865) (FONER, 2017 [2005]; KARNAL et al., 2007).
} 
dental [...]" (OLMSTED, 1852, p. 220-221) ${ }^{14}$. Por conta da recepção favorável do livro pelos norte-americanos e por sua percepção de natureza e contexto social, Olmsted foi convidado, em 1852, por Henry Raymond (1820-1869), editor do The New York Times, para fazer uma série de viagens, entre 1852 e 1854, pelo Sul dos EUA, com o propósito de apresentar uma descrição objetiva do efeito da escravidão sobre as condiçóes ambientais e sociais. O futuro arquiteto de paisagens ampliou sua visão e seus questionamentos relacionados a desigualdades sociais (FEIN, 1972) ${ }^{15}$.

Ainda influenciado pelas discussões relacionadas à sociedade norte-americana, em 1855 Olmsted tornou-se um dos proprietários e editor do Putnam's Monthly Magazine. Tratava-se de um periódico intelectual de vanguarda, voltado para o debate de uma ampla gama de questôes relacionadas com o futuro da nação norte-americana, envolvendo temas sociais, políticos, científicos e estéticos. O darwinismo social, por exemplo, era muito criticado por Olmsted, pois estimulava a competição desenfreada e, consequentemente, maior destruição da natureza, para favorecer as novas tecnologias e a expansão urbana. Apesar de ter ido à falência financeira em 1857, o periódico incutiu uma noção de liberdade, igualdade e propósito em Olmsted, que o impulsionaram a compreender seu contexto social e a envolver-se diretamente na Guerra Civil entre os anos de 1861 e 1863 (FEIN, 1972; MARTIN, 2011) ${ }^{16}$.

Olmsted foi incentivado desde pequeno a observar a paisagem. Com seus pais ele aprendeu a apreciá-la, e na fazenda em Staten Island, ele iniciou seu trabalho com o uso da terra por meio da agricultura. Ele aproveitou os ensinamentos do horticultor Downing sobre as propriedades das plantas e até arriscou-se na arquitetura de paisagens ao planejar a instalação de sua casa em Staten Island. Com suas viagens, Olmsted aprendeu a observar a paisagem e a desenvolver uma visão mais crítica sobre questôes sociais e políticas. Olmsted estava pronto para aplicar todas essas experiências pessoais e profissionais no projeto que o inseriu definitivamente na arquitetura de paisagens, o New York Central Park.

\footnotetext{
${ }^{14}$ No original: "All the more sober and religious people have a great horror of our slavery and of the occasional Lynch-law performances on our western border [...]”. A lei de Lynch referia-se ao linchamento, prática utilizada contra índios e negros nos EUA.

${ }^{15}$ Em Was Olmsted an Unbiased Critic of the South?, Schlesinger (1952) atestou a neutralidade de Olmsted em relação ao tema da escravidão. Essa neutralidade está mais associada à compreensão de ambas as partes dos EUA (Norte abolicionista e Sul escravocrata) do que a uma indiferença à escravidáo. Olmsted defendia um abolicionismo gradual, por receio de que uma aboliçáo abrupta poderia causar um colapso na economia norte-americana. No entanto, ele náo deixou de narrar a situaçáo de vida precária dos escravos do Sul.

${ }^{16}$ Entre os anos de 1861 e 1863, Olmsted trabalhou como secretário executivo da United States Sanitary Comission (USSC), uma organização privada com o objetivo de pesquisar, planejar e coordenar políticas e programas relacionados ao dia a dia dos soldados, como alimentaçáo, tratamentos médicos e abrigo. Atualmente esquecida, a participação da USSC foi de extrema importância na época para amenizar as trágicas consequências da guerra, e deu origem à atual Red Cross (FEIN, 1972; MARTIN, 2011).
} 


\section{A arquitetura de paisagens no Central Park e nos parques nacionais}

Na segunda metade do século XIX, a cidade de Nova York (e demais cidades norte-americanas) passava por problemas estruturais e ambientais advindos de sua expansão, como infraestrutura insuficiente para atender toda a população, alastramento de doenças, surgimento de guetos e aumento de incêndios. Para resolver esses problemas foi adotada uma política de embelezamento e higienismo na cidade. Dentre algumas das soluçóes, os planejadores urbanos e paisagísticos sugeriram a ampliação da largura das ruas, a organização do sistema de transportes e a inserção de parques urbanos. Os parques, em especial as árvores, eram considerados na época como verdadeiros responsáveis pela purificação do ar das cidades, os "pulmôes" das cidades. Em 1857, os comissários da área reservada ao Central Park lançaram um concurso de projetos para o futuro parque. Calvert Vaux convidou Olmsted a colaborar com uma proposta para o concurso. O projeto da dupla, batizado de Greensward Plan, foi o vencedor. Olmsted foi nomeado superintendente do Central Park ainda em 1857, e arquiteto-chefe em 1858 (CARR, 1999; MUMFORD, 1998 [1961]; SEGAWA, 1996; SENNETT, 1994; WELLS, 2014).

O projeto do Central Park de Olmsted e Vaux diferenciava-se de grande parte dos demais projetos concorrentes em um aspecto essencial: os elementos funcionais, em parte sugeridos no edital do concurso, estavam todos subordinados a uma concepção estética da paisagem, o estilo pitoresco trazido da Inglaterra por Downing (CARR, 1999). De acordo com a descrição do plano geral do parque elaborado por Olmsted e Vaux, "O plantio regular e os efeitos arquitetônicos, a menos que em grande escala, devem ser evitados [...]” (OLMSTED, 1858, 1. 2199) ${ }^{17} \mathrm{e}$ "[...] achamos que o interesse do visitante [...] deve se concentrar em características da beleza natural, em vez da artificial" (OLMSTED, 1858, 1. 2343) ${ }^{18}$.

Essa dedicação à paisagem era tão grande que o projeto possuía um guia explicativo do viveiro do parque. Olmsted apropriou-se de seus conhecimentos de horticultura e agricultura - adquiridos principalmente em Staten Island, e também com os artigos que escrevia para o The Horticulturist e com o contato mantido com Downing - para dedicar especial atenção a essa parte, sugerindo as espécies a serem utilizadas e os locais onde seriam plantadas (BEVERIDGE, 2016; CARR, 1999; STOLL, 2015).

Sobre suas características gerais, o New York Central Park foi criado em uma área de 3,41 $\mathrm{km}^{2}$, e dividido topograficamente, na proposta de Olmsted e Vaux, em parque superior e inferior. A parte superior possuía linhas do horizonte que poderiam ser trabalhadas devido a seus amplos declives, uma característica ideal para parques, de acordo com os dois elaboradores do projeto. Interferências de vias e construçôes nessa área deveriam ser evitadas.

\footnotetext{
${ }^{17}$ No original: "Formal planting and architectural effects, unless on a very grand scale, must be avoided [...]". ${ }^{18}$ No original: "[...] we feel that the interest of the visitor [...] should concentrate on features of natural, in preference to artificial, beauty”.
} 
O parque inferior tinha características mais heterogêneas, requerendo tratamentos variados. Em ambos os locais, Olmsted e Vaux trabalharam os elementos - características, bordas, topografia, geologia, circulação e acessos - de maneira que todas as vistas do parque fossem desenhadas como uma antítese da cidade, ora voltando-se para dentro do parque, ora para o horizonte ou para a vegetação (HOLDEN; LIVERSEDGE, 2014) (Figuras 2 e 3).

Além do trabalho com o direcionamento do olhar do visitante, sempre voltado à natureza, Olmsted e Vaux criaram um novo conceito de estradas. Foram estabelecidas quatro estradas transversais ao parque, não retilíneas e construídas abaixo da superfície, de maneira a ficar fora da linha do horizonte do observador. Essas estradas foram chamadas de parkways, e concebidas com essas características para criar uma sensaçáo de ambiente pastoril dentro do ambiente urbano. Os caminhos sinuosos também foram aplicados aos pedestres, o que obrigava o transeunte a observar o ambiente com mais calma (KOSNOSKI, 2011; WELLS, 2014).

$\mathrm{Na}$ relação dos caminhos sinuosos com os espaços do parque, ora amplos, ora mais intimistas, Nicholson (2004) e Kosnoski (2011) afirmam que surgiam dois tipos de interação propostas por Olmsted: gregária e de vizinhança. A primeira ocorria entre estranhos, a segunda relacionava-se a grupos interagindo entre si. Uma interação poderia levar à outra, mas náo necessariamente. A ação de ver e ser visto ao ar livre foi um aspecto indiretamente importado dos jardins britânicos, que uniram o prazer da caminhada e da interação social com a apreciação da natureza. Os tipos de uso do parque fortaleceram o conceito de democrático, relacionado com diversidade e participação (KOSNOSKI, 2011; NICHOLSON, 2004; SEGAWA, 1996). Havia também nessa relação a mesma proposta de civilidade presente em Downing. O contato com a natureza trazia benefícios relacionados ao lazer e à saúde, fazendo com que os cidadãos passassem a valorizar esse contato e zelar pela natureza.

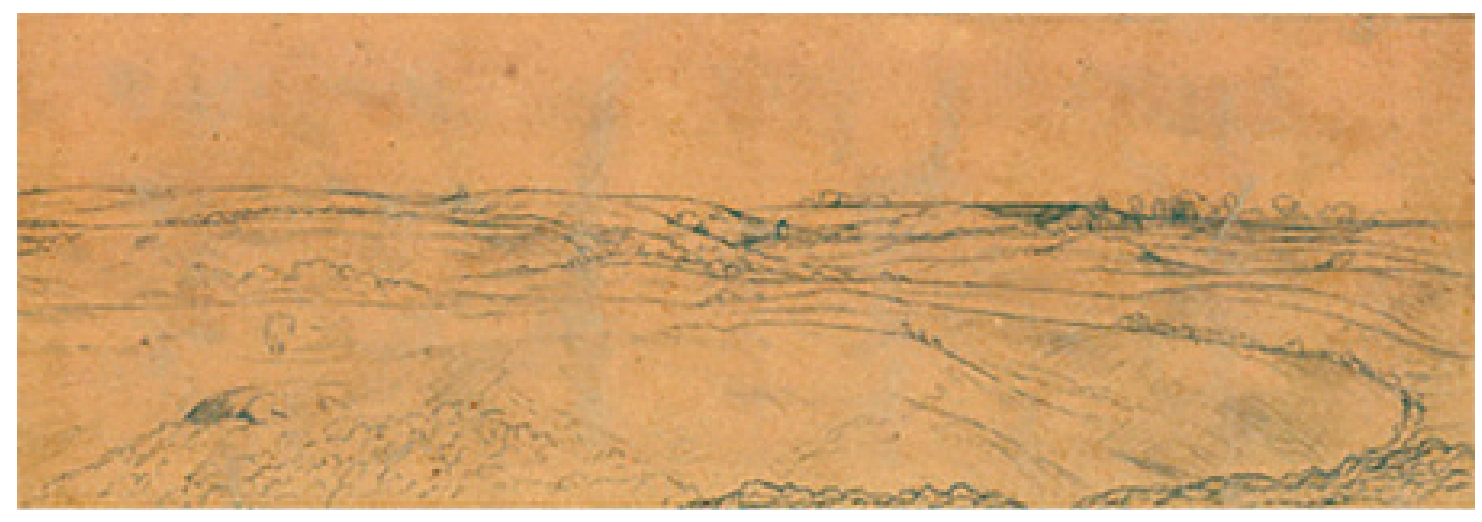

Figura 2: Estudo Greensward Plan, ou Central Park (1857): esboço das linhas existentes na vista sul do parque superior do Bogardus Hill próximo da $103^{\text {rd }}$ Street e Eight Avenue, anterior a qualquer planejamento. Feito por Olmsted e Vaux para o concurso do parque central de Nova York. Fonte: Beveridge (2016, 1. 12355). Cortesia do NYC Municipal Archives 


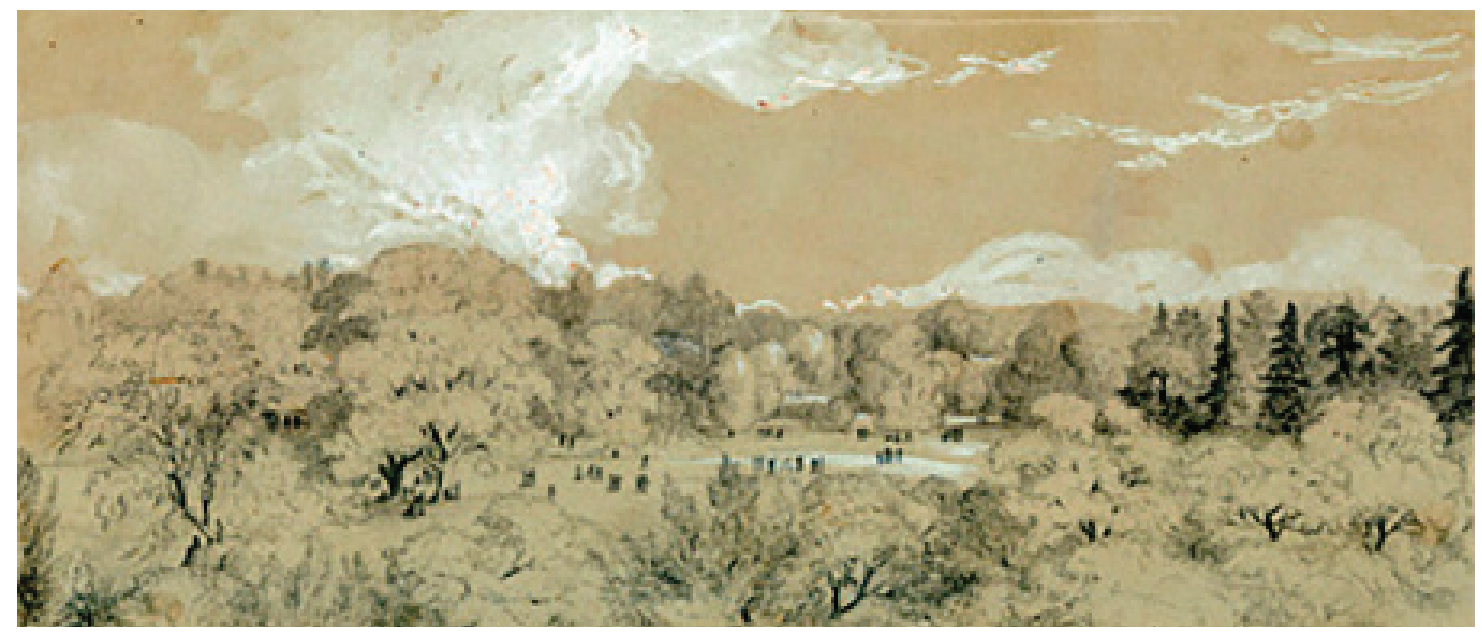

Figura 3: Estudo Greensward Plan, ou Central Park (1857): esboço de proposta para parque de diversóes na vista sul do parque superior do Bogardus Hill próximo da $103^{\text {rd }}$ Street e Eight Avenue.

Feito por Olmsted e Vaux para o concurso do parque central de Nova York.

Fonte: Beveridge (2016, 1. 12362). Cortesia do NYC Municipal Archives

O uso democrático do parque também se refletia na ausência de portóes ou grandes entradas. Em 1863, o arquiteto norte-americano Richard Morris Hunt (1827-1895) foi contratado para projetar portóes para o parque. O estilo de arte usado por ele foi o simétrico e antigo, tão criticado por Downing (1841) e justamente o oposto do estilo pitoresco. Olmsted e Vaux foram contrários à instalação dos portões, alegando que eles alterariam o caráter democrático do planejamento com uma estética aristocrática. Devido às manifestaçóes contrárias de Olmsted e Vaux, o plano de Hunt não foi levado adiante (FEIN, 1972).

O trabalho no Central Park preparou Olmsted para aplicar sua experiência na coordenação de projetos e seu estilo de arquitetura de paisagens no Yosemite Valley. Apesar do conturbado momento político na segunda metade do século XIX, com a Guerra Civil em andamento e a luta pela abolição da escravidão, a proteção da natureza estava começando a ganhar espaço frente à desenfreada marcha para o Oeste, como uma maneira de expressão da identidade nacional norte-americana. Esse reconhecimento, tanto do contexto quanto da luta pela proteção da natureza, apareceu no relatório que Olmsted elaborou para a criação do Parque Nacional do Yosemite, documento analisado em seguida.

$\mathrm{O}$ ato do Congresso do estado da Califórnia, de 30 de junho de 1864, designou a região do Yosemite e o bosque Mariposa Big Tree para uso público e recreação, além de ter declarado o seu caráter como inalienável. O local passou a ser administrado pelo governador da Califórnia, por meio de um grupo de comissários. Olmsted foi o primeiro presidente da comissão, que tinha duas tarefas imediatas: realizar pesquisa e mapeamento da região e elaborar um relatório sobre a política de manejo da concessão da área do vale (CRONON, 1996; FEIN, 1972; MARTIN, 2011). 
Concluídos a pesquisa e o mapeamento, em 8 de agosto de 1865, Olmsted apresentou o seu relatório. Primeiramente, ele não pôde deixar de comentar e lamentar a questáo da Guerra Civil norte-americana. Em seguida, Olmsted ponderou que, apesar da guerra, os esforços para a proteção da wilderness felizmente foram convertidos no ato de 1864 . Ele fez uma descrição detalhada da região e estabeleceu:

\section{[...] É o principal dever do Governo, se não o único dever do Governo, proporcionar meios} de proteçáo a todos os cidadáos na busca da felicidade, ante os obstáculos, de outra maneira intransponíveis, quando o egoísmo dos indivíduos ou da combinação de indivíduos é responsável por interpor àquela busca (OLMSTED, 2014 [1865], 1. 93-120, grifo nosso). ${ }^{19}$

No relatório, Olmsted argumentou que o usufruto dos benefícios do contato com a natureza ficou sob o monopólio de uma elite aristocrática durante muito tempo, e "A grande parte da sociedade, incluindo aqueles para os quais [o contato] seria de grande benefício, é excluída dele" (OLMSTED, 2014 [1865], 1. 176) ${ }^{20}$. Assim, "É necessário que eles (os parques) devam permanecer abertos para o uso do corpo da sociedade" (OLMSTED, 2014 [1865], 1. 1802) ${ }^{21}$ O contato com a natureza, para Olmsted, além de proporcionar lazer e benefícios à saúde mental e física humanos, era um fator de civilidade, assim como o era para Downing: "É um fato importante que, à medida que a civilizaçâo avança, o interesse dos homens em cenas naturais de sublimidade e beleza aumenta" (OLMSTED, 2014 [1865], 1. 230 ${ }^{22}$. Essa mesma liberdade de acesso, a noção de civilidade e o contato com a natureza foram intençôes proporcionadas por Olmsted e Vaux no projeto do New York Central Park. Olmsted também estabeleceu em seu relatório importantes lembretes aos delegados encarregados da administração do parque. "O primeiro ponto a se ter em mente é a preservaçáo e manutenção, tanto quanto possível, do cenário natural [...]” (OLMSTED, 2014 [1865], 1. 207-210) ${ }^{23}$. Observação semelhante foi escrita no Description of a Plan for the Improvement of the Central Park.

Ao considerar ser a valorização e preservação do cenário natural a característica mais marcante do estilo pitoresco, não é de se admirar que ela seja aplicada e reiterada em quase todos os projetos de Olmsted. No caso do parque nacional, essa premissa do estilo pitoresco

\footnotetext{
${ }^{19}$ No original: "[...] It is the main duty of government, if it is not the sole duty of government, to provide means of protection for all its citizens in the pursuit of happiness against the obstacles, otherwise insurmountable, which the selfishness of individuals or combinations of individuals is liable to interpose to that pursuit".

${ }^{20}$ No original: "The great mass of society, including those to whom it would be of the greatest benefit, is excluded from it".

${ }^{21}$ No original: "It is necessary that they should be laid open to the use of the body of the people".

${ }^{22}$ No original: "It is an important fact that as civilization advances, the interest of men in natural scenes of sublimity and beauty increases".

${ }^{23}$ No original: "The first point to be kept in mind then is the preservation and maintenance as exactly as is possible of the natural scenery $[. .$.$] ".$
} 
entra ainda mais em conformidade com a valorização e proteção da natureza, mesmo que inicialmente voltada para o lazer e a saúde humanos. Ainda sobre o estilo aplicado na arquitetura de paisagens, em relaçáo às estradas e trilhas, o mesmo trabalho em linhas sinuosas que foi usado nos caminhos e nas parkways do Central Park, também foi sugerido para o futuro parque: "A trilha ou estrada estreita poderia também ser deixada mais à sombra, poderia trilhar um caminho mais pitoresco [...]” (OLMSTED, 2014 [1865], 1. 274)24. O outro lembrete de Olmsted aos administradores do parque sugere:

Segundo; é importante lembrar que ao permitir o sacrifício de qualquer coisa que seria do mais vago valor para futuros visitantes, por conveniência, mau gosto, brincadeira, falta de cuidado ou destruição deliberada de presentes visitantes, faz com que nós, provavelmente, submetamos, em cada um desses casos, o interesse de incontáveis milhôes ao egoísmo de poucos indivíduos. [...] Em algum momento, portanto, leis para prevenir um uso injusto por indivíduos daquilo que não é individual, mas público, devem ser feitas e rigidamente reforçadas (OLMSTED, 2014 [1865], 1. 226-238). ${ }^{25}$

Contudo, o relatório não foi publicado pela legislatura da Califórnia e, em 1865, Olmsted retornou a Nova York para trabalhar na recuperação das Niagara Falls. Em 1867, ele pediu renúncia do cargo de comissário do parque "que foi aceita pelo governador com expressôes de arrependimento e gratidáo" (OLMSTED, 2016 [s.d.], 1. 11487) ${ }^{26}$. A definiçáo do local como parque nacional ocorreu apenas em 1890, depois de uma campanha bem-sucedida de um dos fundadores do movimento preservacionista, o escritor escocês-americano John Muir (1838-1914). Muir respeitosamente requisitou e assegurou a assistência de Olmsted nessa campanha, como reconhecimento pela luta anterior do arquiteto de paisagens para estabelecer o local como reserva nacional (NASH, 1990).

Apesar da negativa do relatório, o ato de reserva do Yosemite Valley como território público para proteção da natureza e lazer incentivou a proteção de outras áreas. Estava em debate a criação do parque de Yellowstone, efetivada em 1872. Nesse ano, o presidente norte-americano Ulysses S. Grant (1822-1885), pressionado pela população, ciente e influenciada pela criação da reserva do território do Yosemite Valley, sancionou uma lei designando mais de oito mil km² localizados a noroeste de Wyoming para a preservaçáo. A lei tinha como meta preservar as maravilhas naturais, como gêiseres, fontes termais e cânions (NASH, 1990,

\footnotetext{
${ }^{24}$ No original: "The trail or narrow road could also be kept more in the shade, could take a more picturesque course [...]".

${ }^{25}$ No original: "Second; it is important that it should be remembered that in permiting the sacrifice of anything that would be of the slightest value to future visitors to the convenience, bad taste, playfulness, carelessness, or wanton destructiveness of present visitors, we probably yield in each case the interest of uncounted millions to the selfishness of a few individuals. [...] At some time, therefore, laws to prevent an unjust use by individuals of that which is not individual but public property, must be made and rigidly enforced".

${ }^{26}$ No original: "[...] which was accepted by the Governor with expressions of regret and gratitude".
} 
2001 [1967]). A preservação da wilderness não fez parte do plano principal inicial nem do parque de Yosemite, nem de Yellowstone ${ }^{27}$.

Em 1892, vinte anos depois da criação do Parque Nacional de Yellowstone, o senador do Tennessee, William B. Bates, explicou seu propósito de proteger uma regiáo para os norte-americanos que desejavam ver a natureza primitiva, simples e pura. Foi a partir de atitudes como a de Bates que o conceito de wilderness passou a ser adotado como motivaçáo para a criação de parques nacionais nos EUA (NASH, 2001 [1967]). Como Thoreau já argumentava desde meados de 1850, proteger a wilderness era proteger a própria civilização. Bates parece ter compreendido que não era necessário qualquer justificativa para a criação de uma área protegida, justamente porque a proteção em si já era benéfica a todos: humanos, animais, plantas e demais seres bióticos e elementos abióticos.

Se o ato de 1864 impulsionou a criação do Parque Nacional de Yellowstone, as sugestôes passadas pelo relatório de Olmsted de 1865 influenciaram as diretrizes do NPS, agência governamental criada em 1916 para regular os serviços de parques. No relatório, constavam regras sobre construçôes no local, as quais não deveriam ser abundantes para não prejudicar o cenário natural (FEIN, 1972; NASH, 1990). Olmsted ainda propôs a composiçáo e organização do quadro de comissões de parques: "É ainda proposto que dos oito comissários a serem indicados pelo Executivo, quatro devem ser indicados anualmente e que esses quatro devem ser estudantes de Ciências Naturais ou Artistas da Paisagem” (OLMSTED, 2014 [1865], 1. 300) $)^{28}$.

O Organic Act de 1916, que criou o NPS, contou com a colaboração de Frederick Law Olmsted Jr. (CARR, 1999; STOLL, 2015). Um dos trechos mais famosos do ato foi de sua autoria e estabelecia a função do NPS: "[...] conservar a paisagem e os objetos naturais e históricos e a vida selvagem nela contida e proporcionar o desfrute do mesmo da maneira e por meios que os deixem inalterados para o desfrute das geraçóes futuras" (SENATE AND HOUSE OF REPRESENTATIVES OF THE UNITED STATES OF AMERICA IN CONGRESS, 1916) ${ }^{29}$. Trecho semelhante ao de Olmsted para o relatório de 1865.

Em relação à composição do NPS, ela não foi idêntica à composição do quadro de comissóes proposto por Olmsted. Entretanto, a sua sugestão de contratar artistas da paisagem estava presente no quadro organizacional do NPS. De 1919 a 1927, a arquitetura de paisagens

\footnotetext{
${ }^{27}$ Nash em Wilderness and the American Mind (2001), capítulo 7 (Wilderness preservada) exemplifica o caráter utilitarista envolvendo a delimitação para preservação da região de Yellowstone. A estratégia para sua proteção foi de demonstrar justamente sua "inutilidade" para a civilização. Não havia terras férteis, nem interesse em bacias hidrográficas, apenas belezas naturais. Já no Yosemite Valley havia interesses nas fontes hídricas locais, tanto que a região foi palco de conflitos sobre a construçáo da represa de Hetch-Hetchy, iniciada em 1913. ${ }^{28}$ No original: "It is also proposed that of the eight Commissioners to be appointed by the Executive, four shall be appointed annually and that these four shall be students of Natural Science or Landscape Artists". ${ }^{29}$ No original: "[...] to conserve the scenery and the natural and historic objects and the wild life therein and to provide for the enjoyment of the same in such manner and by such means as will leave them unimpaired for the enjoyment of future generations".
} 
destacou-se no quadro organizacional ao lado de poucos departamentos, entre eles atendimento, engenharia, assistência editorial, educação da história nacional, assistência em operaçóes públicas e advocacia. A partir de 1928, a silvicultura passou a constar do quadro e a competir com a arquitetura de paisagens. Esse embate entre arquitetura de paisagens e silvicultura prolongou-se por grande parte da história do NPS, que é, ainda hoje, o órgão que regula os parques nacionais norte-americanos (CARR, 1999; LAURIE, 1976; SELLARS, 1997).

Após diversos trabalhos em arquitetura de paisagens, em junho de 1893 Olmsted recebeu o diploma de doutor em lei (LL.D. degree) pelas universidades de Harvard e Yale, como um reconhecimento à sua contribuiçáo na luta pela democracia e também pela proteçáo da natureza. Ele continuou sua produção de projetos em meios urbanos e naturais até o ano de 1895, quando aposentou-se voluntariamente devido ao agravamento de uma doença incapacitante. No ano seguinte, ele já estava completamente inválido. Olmsted faleceu no dia 28 de agosto de 1903, em Belmont, Massachussetts (FEIN, 1972). Além de suas contribuições por meio de projetos e de participaçóes na vida política, ele também oficializou, em 1858, o termo "arquitetura de paisagens". Em 1901, o primeiro programa universitário completo em arquitetura de paisagens foi criado na Harvard University sob a direção de Olmsted Jr. (FEIN, 1972; LAURIE, 1976; STOLL, 2015).

\section{Considerações finais}

Olmsted foi um homem de seu tempo, e foi justamente sua contextualização que fez com que proporcionasse uma das melhores maneiras de se trabalhar a paisagem. Seu estilo pitoresco, influenciado pelo romantismo, valorizava o contato com a natureza como uma forma de proporcionar civilidade. Para tal finalidade, o acesso deveria ser livre a todos, para que a sociedade se beneficiasse do que um ambiente natural poderia proporcionar. $\mathrm{O}$ trabalho de Olmsted buscava, dessa maneira, a contemplaçáo da natureza para a evoluçáo humana.

Não se pode dizer que Olmsted tinha como foco único a proteção da natureza, pois para ele sociedade e natureza tinham o mesmo peso. Sua visão de proteção se encaixava mais no conservacionismo, ou seja, no uso racional dos recursos naturais. $\mathrm{O}$ fato de criar edificaçóes, trilhas e demais facilidades para a visitaçáo de parques nacionais e mesmo urbanos, pode parecer uma contradição para a proteção da wilderness inicialmente. Mas é justamente a visitaçáo que faz com que as pessoas entrem em maior contato com a natureza e desejem protegê-la. Isso foi relutantemente reconhecido até mesmo pelo preservacionista John Muir, que admitiu que o turismo seria capaz de unir pessoas na defesa dos parques nacionais (NASH, 2001 [1967]).

Além de estabelecer as bases para o trabalho da arquitetura de paisagens nos parques urbanos e nacionais, sugerindo a valorização do cenário natural e pouca interferência ar- 
quitetônica, Olmsted proporcionou condiçôes e até mesmo diretrizes para o futuro NPS. Um dos objetivos principais da organização, estabelecido por Olmsted Jr., já estava presente no relatório que seu pai elaborou em 1865 para a criação do Parque Nacional do Yosemite, comprovando a continuidade da influência dos trabalhos e dos ideais de Olmsted.

\section{Fontes}

BEVERIDGE, Charles (ed.). Frederick Law Olmsted: Writings on Landscape, Culture and Society. New York: Library of America, 2016.

DOWNING, Andrew J. A Treatise on the Theory and Practice of Landscape Gardening, Adapted to North America: With a View to the Improvement of Country Residences. 1. ed. New York \& London: Wiley and Putnam, 1841.

GILPIN, William. Remarks on forest scenery, and other woodland views (related chiefly to picturesque beauty), illustrated by the scenes of New Forest in Hampshire. London: Printed for R. Blamire, Strand, 1791.

HUBBARD, Theodora K.; OLMSTED JR., Frederick Law (eds.). Frederick Law Olmsted, Landscape Architect, 1822-1903 (v. 1) (1922). Miami, Florida: Hardpress Publishing, 2018.

OLMSTED, Frederick Law. [Correspondência]. Destinatário: Andrew Jackson Downing (1850). In: HUBBARD, Theodora K.; OLMSTED JR., Frederick Law (eds.). Frederick Law Olmsted, Landscape Architect, 1822-1903 (v. 1) (1922). Miami, Florida: Hardpress Publishing, 2018.

OLMSTED, Frederick Law. [Correspondência]. Destinatário: uma amiga (1890). In: HUBBARD, Theodora K.; OLMSTED JR., Frederick Law (eds.). Frederick Law Olmsted, Landscape Architect, 1822-1903 (v. 1) (1922). Miami, Florida: Hardpress Publishing, 2018.

OLMSTED, Frederick Law. Nothing of an artificial character (s.d.). In: BEVERIDGE, Charles (ed.). Frederick Law Olmsted: Writings on Landscape, Culture and Society. New York: Library of America, 2016.

OLMSTED, Frederick Law. Passages in the Life of an Unpractical Man (s.d.). In: HUBBARD, Theodora K.; OLMSTED JR., Frederick Law (eds.). Frederick Law Olmsted, Landscape Architect, 1822-1903 (v. 1) (1922). Miami, Florida: Hardpress Publishing, 2018. OLMSTED, Frederick Law. The Greensward Plan: April 1858 (1858). In: BEVERIDGE, Charles (ed.). Frederick Law Olmsted: Writings on Landscape, Culture and Society. New York: Library of America, 2016.

OLMSTED, Frederick Law. The Yosemite Valley and the Mariposa Grove of Big Trees: a Preliminary Report, 1865 (1865). California: Yosemite Association, 2014. 
OLMSTED, Frederick Law. Walks and talks of an American farmer in England (v. 1). New York: G. P. Putnam, 1852.

PRICE, Uvedale. Essays on the Picturesque, as Compared with the Sublime and the Beautiful: and, on the Use of Studying Pictures, for the Purpose of Improving Real Landscape (v. 1). Massachusetts: Mawman, 1810.

\section{Referências}

CARR, Ethan. Wilderness by Design: landscape architecture and the National Park Service. Nebraska: University of Nebraska Press, 1999.

CRONON, William. Uncommon Ground: rethinking the human place in nature. New York: W. W. Norton \& Company, 1996.

EMIDIO, Teresa M. Meio ambiente \& paisagem. São Paulo: Editora Senac, 2017.

FEIN, Albert. Frederick Law Olmsted and the American environmental tradition. New York: G Braziller, 1972.

FONER, Eric. Give me Liberty! An American History (v. 1: to 1877) (2005). 5. ed. New York, London: W. W. Norton \& Company, 2017.

HOLDEN, Robert; LIVERSEDGE, Jamie. Beginning a Project. In: KING, Laurence (ed.). Landscape Architecture: an introduction. London, United Kingdom: Laurence King Publishing, 2014. p. 41-56.

KARNAL, Leandro et al. História dos Estados Unidos: das origens ao século XXI. São Paulo: Contexto, 2007.

KOSNOSKI, Jason. Democratic vistas: Frederick Law Olmsted's parks as spatial mediation of urban diversity. Space and Culture, v. 14, n. 1, p. 51-66, 21 fev. 2011.

KOWSKY, Francis. Country, Park \& City: the architecture and life of Calvert Vaux. New York: Oxford University Press, 2003.

LAURIE, Michael. Introduction to landscape architecture (an). New York: American Elsevier Publishing Company, 1976.

MARTIN, Justin. Genius of Place: the life of Frederick Law Olmsted. Cambridge, Massachusetts: Da Capo Press, 2011.

MUMFORD, Lewis. A cidade na história: suas origens, transformaçôes e perspectivas (1961). 4. ed. São Paulo: Martins Fontes, 1998.

NASH, Roderick F. The Rights of Nature: a history of environmental ethics. Wisconsin: Wisconsin University Press, 1989. 
NASH, Roderick F. American Environmentalism: readings in conservation history. New York: McGraw-Hill, 1990.

NASH, Roderick F. Wilderness and the American Mind (1967). 4. ed. New Haven: Yale University Press, 2001.

NICHOLSON, Carol J. Elegance and grass roots: the neglected philosophy of Frederick Law Olmsted. Transactions of the Charles S. Pierce Society, v. XL, p. 335-348, 2004.

PANZINI, Franco. Projetar a natureza: arquitetura da paisagem e dos jardins desde as origens até a época contemporânea. São Paulo: Editora Senac, 2013.

SCHLESINGER, Arthur M. Was Olmsted an unbiased critic of the South? The Journal of Negro History, v. 37, n. 2, p. 173-187, abr. 1952.

SEGAWA, Hugo. Ao amor do público - jardins no Brasil. São Paulo: Studio Nobel, 1996.

SELLARS, Richard W. Preserving Nature in The National Parks. New Haven: Yale University Press, 1997.

SENATE AND HOUSE OF REPRESENTATIVES OF THE UNITED STATES OF AMERICA IN CONGRESS. Organic Act of 1916. Disponível em: https://www.nps.gov/ grba/learn/management/organic-act-of-1916.htm. Acesso em: 11 out. 2019.

SENNETT, Richard. Flesh and Stone: the body and the city in Western civilization. New York: W. W. Norton \& Company, 1994.

STOLL, Mark. Inherit the Holy Mountain: religion and the rise of American environmentalism. England: Oxford University Press, 2015.

WELLS, Christopher. Rebuilding the city, leaving it behind: transportation and the environmental crisis in turn-of-the-century American cities. Journal of Transport History, v. 35, n. 2, p. 183-199, 2014. 